\title{
Correction to: Congruency of intervening events and self-induced action influence prediction of final results
}

\author{
Tsukasa Kimura' ${ }^{1}$ - Jun'ichi Katayama ${ }^{2,3}$
}

Published online: 9 April 2020

(c) The Author(s) 2020

\section{Correction to: Experimental Brain Research https://doi.org/10.1007/s00221-020-05735-9}

The article Congruency of intervening events and selfinduced action influence prediction of final results written by Tsukasa Kimura and Jun'ichi Katayama was originally published Online First without Open Access. After publication in volume 238 , issue 3 , page $575-586$ the author decided to opt for Open Choice and to make the article an Open Access publication. Therefore, the copyright of the article has been changed to $(\odot$ The Author(s) 2020 and the article is forthwith distributed under the terms of the Creative Commons Attribution 4.0 International License (https:// creativecommons.org/licenses/by/4.0/), which permits use, duplication, adaptation, distribution and reproduction in any medium or format, as long as you give appropriate credit to the original author(s) and the source, provide a link to the Creative Commons license, and indicate if changes were made.

The original article has been corrected.

Publisher's Note Springer Nature remains neutral with regard to jurisdictional claims in published maps and institutional affiliations.

The original article can be found online at https://doi.org/10.1007/ s00221-020-05735-9.

Tsukasa Kimura

kimura@ai.sanken.osaka-u.ac.jp

Jun'ichi Katayama

jkatayama@kwansei.ac.jp

1 The Institute of Scientific and Industrial Research (ISIR), Osaka University, Ibaraki 567-0047, Japan

2 Department of Psychological Science, Kwansei Gakuin University, Nishinomiya, Japan

3 Center for Applied Psychological Science (CAPS), Kwansei Gakuin University, Nishinomiya 662-8501, Japan 